\title{
Anterior Cruciate Ligament Injury in Collegiate Female Dancers
}

\author{
Jatin P. Ambegaonkar, PhD, ATC • George Mason University \\ Sandra J. Shultz, PhD, ATC, FNATA, David H. Perrin, PhD, ATC, \\ and Mark R. Schulz, PhD - University of North Carolina at Greensboro
}

\footnotetext{
***Reprinted with permission. No further reproduction is authorized without written permission from the Human Kinetics. This version of the document is not the version of record. Figures and/or pictures may be missing from this format of the document.***
}

\begin{abstract}
A 80,000 to 250,000 anterior cruciate ligament (ACL) injuries of the knee occur annually, with many of these injuries affecting individuals between the ages of 15-25 years.' The majority of ACL injuries are noncontact in nature, ${ }^{2,3}$ with landing and plantand-cut maneuvers being the most common activities associated with it. ${ }^{4}$ Females par-
\end{abstract}

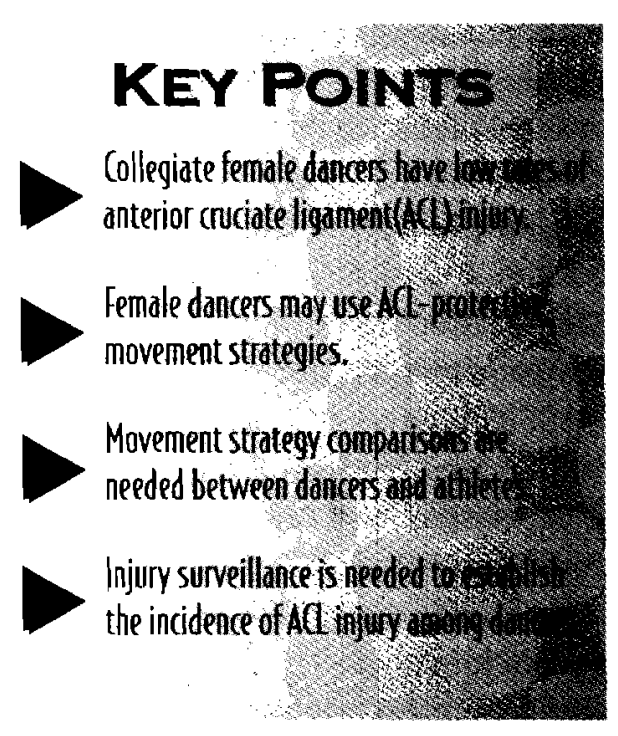
ticipating in sports that involve jump landing and plant-and-cut type activities have a risk level that is $3-8$ times greater than that for males during similar activities. ${ }^{3.4}$ Anatomical, hormonal, neuromuscular, and biomechanical differences have been suggested to be the major factors that explain this injury bias. ${ }^{15,6}$

Female dancers regularly perform multiple landing, jumping, and plant-and-cut type activities ${ }^{7}$ but do not appear to injure the ACL as frequently as do female athletes in jump and land-intensive sports. ${ }^{1,8.9}$ Although ACL injury rates for professional dancers have been reported, ${ }^{10.11}$ we found no published studies reporting ACL injury rates for female collegiate dancers at the university level. Therefore, our objective was to retrospectively determine the prevalence of $A C L$ injuries in a cohort of female collegiate dance students.

\section{Study Background}

Female dance students numbering 145 (21.9 $\pm 3.9 \mathrm{yrs}$, years of dance experience $=12.3$ $\pm 5.7 \mathrm{yrs}$ ) participated in the study. A retrospective cross-sectional injury surveillance design was employed. All participants completed standard health-history questionnaires as part of the university's on site dance medicine preparticipation screening procedures. If a history of knee injury was indicated on the health-history questionnaires, the dancer was interviewed to define the exact nature of the knee injury. For participants who specifically reported a history of $A C L$ injury, information acquired included the exact activity being performed when the ACL injury occurred, how the injury was diagnosed, the clinical course of the injury, and management of the injury.

Of the 145 participants who completed the health history questionnaire, $33 \%(n=$ 48 ) reported a history of knee injury. Only two participants (1.38\%) reported the previous occurrence of ACL injury. Neither injury 
occurred during a dance performance. No surgical intervention was performed for either case.

The first case was documented in the participant's dance medicine program records. The injury occurred when the dancer was warming up before a performance. The mechanism was a plant-and-cut twisting motion. The injury was diagnosed as a firstdegree ACL sprain by an athletic trainer, who referred her to a sports medicine physician. Due to financial considerations, no imaging was performed to confirm the clinical diagnosis. Conservative treatment was instituted, which included rest, cryotherapy, over-thecounter pain medication, and rehabilitative exercises. The dancer returned to full participation within four weeks postinjury.

The other case of ACL injury was occurred approximately four years prior to the data collection interview. Although the participant did not remember the exact activity being performed when the injury occurred, she reported that the injury occurring during participation in a recreational physical activity unrelated to dance (unorganized play with friends). An orthopedic surgeon diagnosed an ACL sprain that was confirmed by magnetic resonance imaging, and the injury was managed conservatively. The dancer reported having participated in a rehabilitative exercise program for a couple of months and subsequently returning to dance activity.

\section{Discussion}

In general agreement with our findings, a low incidence of ACL injury has been reported for professional dancers by Meuffels and Verhaar ${ }^{10}$ (6 ACL injuries in 253 dancers over a 10-year retrospective study period) and Liederbach et al." (12 ACL injuries in 298 dancers over a 5-year prospective study period). In contrast, a 6-8\% $\mathrm{ACL}$ injury rate has been reported for female collegiate athletes who participate in sports that involve jumping. landing, and plant-and-cut maneuvers, such as soccer and basketball. ${ }^{2.3}$ Our study provides verification of a low ACL injury rate among female collegiate dancers.

Several factors may contribute to the low incidence of ACL injury among dancers. Previous research has demonstrated different neuromuscular activation patterns between dancers and other active individuals, which suggests that female dancers have a greater capability for muscle cocontraction. ${ }^{12,13}$ Cocontraction of antagonistic muscle groups has been suggested to protect the knee joint through increased joint stiff- ness during dynamic activity. ${ }^{14-16}$ More research is needed, however, to confirm that dancers possess a superior capability for cocontraction during activity in comparison to other female athletes. Dancers have also been suggested to have a well-developed ability to maintain postural balance, secondary to years of disciplined training. ${ }^{11.17,18}$ Postural balance is believed to be a factor that reduces risk for musculoskeletal injury. ${ }^{19}$ No specific comparison of static or dynamic balance capabilities between female dancers and other physically active females exists in the literature.

The environment and the nature of the activity performed may contribute to the lower ACL injury rate for dancers. Movement patterns in dance are usually choreographed and anticipated, " whereas the movement patterns associated with comperitive sports are reactive to real-time game demands that are unpredictable. Previous research has demonstrated increases in muscle activity and cocontraction during unanticipated movements as compared with anticipated movements, ${ }^{20}$ but the extent to which such muscle activation differences actually reduce $A C L$ injury risk is unclear and warrants further investigation.

Task demands also differ between dance and athletics. In athletics, movements are primarily resultoriented (e.g., scoring a goal or making an accurate throw) without concern for movement aesthetics. In dance performances, however, there is an added requirement for maintenance of visually pleasing aesthetics throughout the performance of a movement pattern. A comparison of quadriceps muscle strength and electromyographic muscle activity between dancers and matched active subjects demonstrated that dancers produced greater quadriceps muscle force output during isometric testing, but they did not jump higher. ${ }^{18}$ Moreover, despite the observation that dancers generated similar quadriceps force output during the performance of jumps, they demonstrated lower levels of electromyographic activity than the comparison group. The researchers suggested that the dancers might have subconsciously down-modulating jump height and maximal muscle activity for aesthetics. ${ }^{18}$ Because a high level of quadriceps activation has been identified as a risk factor for ACL injury, ${ }^{1,5,6,9,21 .}$ ${ }^{23}$ a subconscious down-modulation of quadriceps muscle contraction in dancers may be ACL-protective during activity. Further research is needed to validate this theory.

Unlike athletes who perform sport activities while wearing specialized shoes, dancers may perform in 
footwear (e.g., ballet dance, tap dance), or they may nor (e.g., modern dance). Footwear has been reported to affect movement mechanics. ${ }^{24}$ The risk of sustaining an $\mathrm{ACL}$ injury has been reported to be greater in foorball players who wear shoes having a large number of cleats, which has been associated with increased torsional resistance at the foot-turf interface. ${ }^{25}$ The extent to which footwear affects ACL injury risk needs further investigation. ${ }^{1.5 .6}$

Due to our retrospective study design, we could not accurately document injury exposure. Our purpose was simply to document the prevalence of prior ACL injury among collegiate dancers. Estimation of the ACL injury incidence rate as a function of lifetime dance participation among our 145 participants $(12.3 \pm 5.7 \mathrm{yrs})$ yields a rate of 1.12 per 1,000 dancer-years. Because this was a retrospective cross-sectional study, survivor bias may affect the estimated rate of ACL injury. Furthermore, reliance on participant recall of past injury status represents à major limitation. ${ }^{26.27}$ Gabbe et al. ${ }^{27}$ reported that $80 \%$ of individuals were able to accurately recall the general body region affected by an injury at 12 months postinjury, but few were able to accurately recall the diagnosis. Thus, our participants who recalled having experienced a knee injury may not have provided accurate information about the exact diagnosis, injury progression, and treatment.

Injuries in dance can vary by the type of dance performed. ${ }^{28}$ Although participants took several classes in modern dance, they also practiced orher dance forms. They also were likely to have received training in other dance forms over their lifetime dance histories. The possible influence of dance form on ACL injury risk in dancers is unknown. A recent study reported a 3-5 times greater relative risk of $A C L$ injury in professional modern dancers in comparison to professional ballet dancers. "Further research needs to be conducted to confirm this finding for different levels of dance (e.g., high school, university) at multiple institutions.

Our results suggest that female collegiate dancers have low relative risk for $\mathrm{ACL}$ injury compared to female athletes who participate in sports that involve repetitive landing and cutting maneuvers (e.g., basketball and soccer). Female dancers may develop neuromuscular characteristics and biomechanical movement strategies that are ACL-protective during performance of high-risk activities. Future research needs to determine whether or not dancers utilize muscle activation patterns that increase joint stiffness during activity in a manner that reduces ACL injury risk.

\section{Clinical Application}

Dance medicine is an emerging practice serting for athletic trainers. ${ }^{29}$ Our finding suggests that female collegiate dancers have lower rates of ACL injury than other female athletes, despite regular performance of movements that present risk for ACL injury. Athletic trainers should consider balance training exercises that are similar to those utilized in dance as a strategy for reduction of ACL injury risk in female athletes..$^{30}$

\section{References}

1. Griffin L, Albohm MJ, Árendt EA, Bahr R, Beynnon BD, Demaio M, et al. Understanding and preventing noncontact anterior cruciate ligament injuries: a review of the Hunt Valley II meeting, January 2005. Am J Sports Med. 2006:34(9):1212-32.

2. Agel J, Olson DE. Dick R, Arendt EA, Marshall SW. Descriptive epidemiology of collegiate women's basketball injuries: national collegiate athletic association injury surveillance system, 1988-1989 through 2003-2004. J Athl Train. 2007(42):202-210.

3. Dick RW. Putukian M. Agel J. Evans TA, Marshall SW. Descriptive epidemiology of collegiace women's soccer injuries: National Collegiate Athletic Association injury surveillance system, 1988-1989 through 2002-2003. J Athl Train. 2007;42(2):278-285

4. Arendt EA. Agel J, Dick R. Anterior cruciate ligament injury pacterns among collegiate men and women. J Athl Train. 1999;34(2).86-92.

5. Hewett TE, Myer GD, Ford KR. Anterior cruciate ligament injuries in female athletes: part 1, mechanisms and risk factors. Am J Sports Med. 2006:34(2):299-311

6. Renstrom P, Ljungqvist A, Arendt E, Beynnon B, Fukubayashi T, Garrett W. et al. Non-contact ACL injuries in female athletes: an International Olympic Committee current concepts statement. Br J Sport Med. 2008,42(6):394-412

7. Liederbach MJ, Richardson M. Rodriguez M. Compagno J, Dilgen FE, Rose DJ. Jump exposures in the dance training environment: a measure of ergonomic demand J Athl Train. 2006:41:S85.

8. Scioscia TN, Griffin JR, Fu FH. Knee ligament and meniscal injuries in dancers. $J$ Dance Med Sci. $2001: 5(1): 11-15$.

9. Ireland ML. The female ACL: Why is it more prone to injury. Orthop Clin North Am. 2002:33:637-651

10. Mueffels DE, Verhaar JAN. Ancerior cruciate ligament injury in professional dancers. Acta Orthop. 2008:79(4):515-518.

11. Liederbach MJ, Dilgen FE, Rose DJ. Incidence of anterior cruciate ligament injuries among elice baller and modern dancers: a 5-year prospective study. Am J Sports Med. 2008;36(9): 1779-1788.

12. Nielson J, Crone C. Hultborn H. H-reflexes are smaller in dancers from the Royal Danish Ballet than in well-trained athletes. Eur J Appl Physiol. 1993:66:116-121.

13. Mynark RG. Koceja DM. Comparison of soleus H-reflex gain From prone to standing in dancers and controls. Electroencephalogr Clin Neurophysiol. 1997:10(5):135-140.

14. Draganich LF, Jaeger RJ. Kralj AR. Coactivation of the hamstrings and quadriceps during extension of the knee. $J$ Bone joint Surg. 1989;71(A):1075-1081.

15. Baratta R, Solomonow M, Zhou BH, Leston D, Chuinard R. D'Amrosia R. Muscular coactivation: the role of the antagonist musculature in maintaining knee stability. Am J Sports Med. 1988:16(2):113-122.

16. Wojtys EM. Ashton-Miller JA, Huston L. A gender-related difference in the contribution of the knee musculature co sagittal-plane shear stiffness in subjects with similar knee laxicy. J Bone Joint Surg. 2002,84(A): 10-16 
17. Crots D. Thompson B, Nahom M, Ryan S, Newton RA Balance abil ties of professional dancers on select balance lests. J Orthop Sports Phys Ther. 1996;23(1):12-7.

18. Harley YX, Gibson AS. Harley EH, Lambert M. L. VC, Noakes TD. Quadriceps strength and jumping efficiency in dancers $I$ Dance Med Sci. 2002;6(3):87-94

19. McGuine TA. Greene J]. Best T, Leverson $\mathrm{C}$. Balance as a predicror of ankle injuries in high school basketball players. Chin $\mathrm{J}$ Sport Med $2000 ; 10: 239-244$

20. McLean SG, Lipfert SW. Van den Bogert AJ. Effect of gender and defensive opponent on the biomechanirs of sidestep cunting Med Sci Sports Exerc. 2004:3616):1008-16

21. DeMorat $G$, Weinhold $P$, Blackburn T, Chudik $\$$, Garretl WE aggressive quadriceps loading can induce noncontact anterior cruclate ligament injury. Med Sci Sports Exerc. 2004:32(2):477.783.

22. Li G, Rudy TW, Sakane M, Kanamori A, Ma CB, Woo SLY. The importance of quadriceps and hamstring muscle loading on knee kinematics and in-situ forces in the ACL. J Biomech. 1999;32(4):395-400.

23. Shimokochi $Y$, Shulz 5 ] Mechanisms of noncontact anterior cruciate ligament injury. Aht Train. 2008,43(4):396-408.

24. Bishop M. Fiolkowski P. Conrad B. Brunc D. Horodyski M. Athletic loowear. leg stiffness, and running kinematics. A Athl Train. $2006.41(4): 387.392$

25 Lambson RB. Barnhill BS. Higgnts RW. Football cleat design and its effect on anterior cruciate ligamen injuries: a 3-year prospective study. Am J Sports Med. 1996:24:155-159
26. Valuri $G$, Stevenson M, Finch $C$, Hamer $P$, Ellot $B$. The validiry of 2 four week self-recall of sports injuries inj Prev $2005: 11: 135.137$.

27. Gabbe $B$ J. Finch $C F$, Bennell $K L$, Wajswelner $H$. How valid is a sell reported 12 month sports injury history? Br/Sport Med. 2003,37.524. 547

28. Solomon R. Micheli L. Technique as a consideration in modern dance injuries. Phys Sportsmed. 1986;14:8183-90.

29. Ambegaonkar JP, Caswell SV. Dance program administrators percetions of athletic training services. Athl Ther Today/2009;143):17-i9

30. DiNubile NA $Q \propto$ A on spors medicine for dancers. Ath Ther Todoy $2002,7(2): 8-11$

Jatin P. Ambegaonkar is an assistant professor in the Recreation health and Tourism Department at George Mason University in Faiffax. VA.

Sandra J. Shultz is an associate professor of Exercise and Sport Science at The University of North Carolina at Greensboro

David H. Perrin is a professor in the Department of Exercise and Sport Science at the University of North Carolina at Greensboro.

Mark R. Schuly is an assistant professor in the Department of Public Heaith Education at the Universivy of North Carolina at Greensboro

\section{Incorporate functional progressions into rehabilitation programs}

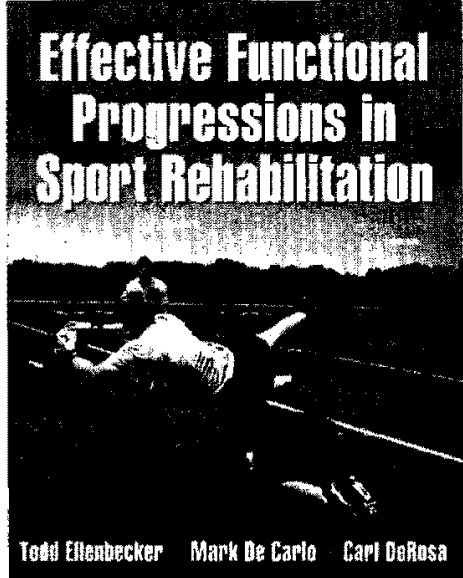

(02009 * Paperback * Approx. 248 pp Print: ISBN 978-0-7360-6381-4 $\$ 39.00(\$ 48.95 \mathrm{CDN}, \pm 28.00 \mathrm{UK}$ E36.40 EURO, $\$ 59.95$ AUS, $\$ 79.00 \mathrm{NZ})$ E-Book ISBN 978-0-7360-8593-9 $\$ 22.00<\$ 27.95 \mathrm{CDN}$, $£ 19.00$ UK ind. VAT, $€ 20.90$ EURO, $\$ 34.10$ AUS, $\$ 45.00 \mathrm{NZ}$

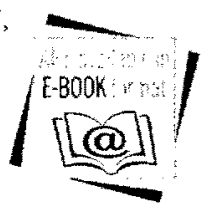

Audiences: Reference for pbysical therapist, athletic trainers, and other sports medicine and rehabilitation specialist; also a text for courses in sport rebabilitation curriculums.

Effective Functional Progressions in Sport Rehabilitation provides clinicians with the strategies and tools they need to prepare their clients for the physical demands required by their sport. This complete reference helps clinicians understand the important concepts of functional progressions and equips them to develop rehabilitation programs specific to the needs of their clients. The authors break down the text into three regional areas-upper extremities, lower extremities, and trunk-before delving in to the specific anatomical and biomechanical differences within each area. They also present the neuromuscular basis for the specific approaches to each region and provide exercises in functional progressions that simulate the activity the athlete needs to perform to be effective in his or her sport again.

Effective Functional Progressions in Sport Rehabilitation also includes key code access to an online resource that allows users access to every image from the text as well as sample templates in both Microsoft Word and PowerPoint. Clinicians can use the images and Word template to create custom handouts for their clients and instructors can make custom presentarions with the PowerPoint template. The images and sample templates are available at www.HumanKinetics.com/EffectiveFunctionalProgressionsinSportRehabilitation

College Instructors: To receive an exam copy, please visit www.HumanKinetics.com/Faculty.

Fot a complete description or to order, call: (800) 747-4457 US * (800) 465-7301 CDN $44(0) 113-255-5665 \mathrm{UK} \cdot(08) 8372-0999$ AUS (09) 448-1207 NZ : (217) 351-5076 International The Information Leader in Physical Activity Or visit www.HumanKinetics.com! 